\title{
ACTUATOR SATURATION AND ITS INFLUENCE ON VIBRATION REDUCTION BY ACTIVELY CONTROLLED FLAPS
}

\author{
R. Cribbs* and P.P. Friedmann ${ }^{\dagger}$ \\ Department of Aerospace Engineering \\ University of Michigan \\ Ann Arbor, Michigan 48109-2140
}

\begin{abstract}
The influence of actuator saturation on the vibration reduction abilities of an actively controlled flap is investigated. An aeroelastic model of a four bladed hingeless rotor with a free wake is used for the analyses. Three methods for constraining flap deflections are studied at two limiting values, two and four degrees, of maximum flap deflection. Results indicate that neither scaling nor clipping of the optimal control flap deflection to the maximum flap deflection provides acceptable vibration reduction. A newly developed control method with saturation constraints shows exceptional reduction of vibrations. This new control method reduces vibrations to similar levels as the unconstrained optimal control while constraining maximum flap deflections to the limiting values.
\end{abstract}

\section{Nomenclature}

$\begin{array}{ll}a & \text { Blade lift curve slope } \\ c_{b} & \text { Blade chord } \\ c_{c s} & \text { Trailing edge flap chord } \\ C_{d o} & \text { Coefficient of drag } \\ C_{W} & \text { Helicopter coefficient of weight } \\ c_{w u} & \text { Weighting multiplier for } \mathbf{W}_{\mathbf{u}} \\ E I_{y}, E I_{z} & \text { weighting matrix } \\ & \text { Blade bending stiffnesses in flap } \\ & \text { and lead-lag }\end{array}$

FHX, FHY, FHZ 4/rev vibratory hub shears in longitudinal, lateral and vertical directions, respectively

$J \quad$ Quadratic performance index for vibration control

* Postdoctoral Scholar; currently Dynamics Engineer, Sikorsky Aircraft, Stratford, CT 06497, Member AIAA

${ }^{\dagger}$ François-Xavier Bagnoud Professor of Aerospace Engineering, Fellow AIAA, Member ASME, AHS

Copyright (C)2001 by Richard C. Cribbs and Peretz P. Friedmann. Published by the American Institute of Aeronautics and Astronautics, Inc. with permission.
$L_{b}$
$L_{c s}$
$m$

MHX, MHY, MHZ 4/rev vibratory hub moments in rolling, pitching and yawing, respectively

$\begin{array}{ll}n_{b} & \text { Number of blades } \\ R & \text { Rotor radius }\end{array}$

$R \quad$ Rotor radius

$T$

Jacobian of the vibration response with respect to the control input

$\vec{u}$

Vector of control inputs

$\vec{u}^{*}$

$\mathbf{W}_{\mathbf{u}}$ Vector of optimal control inputs Matrix of weights on control amplitudes

$\mathbf{W}_{\mathbf{z}}$

$\mathrm{W}_{\Delta \mathrm{u}}$

$x_{c s}$

$X_{F A}, X_{F C}$

$\vec{z}$

$Z_{F A}, Z_{F C}$

Matrix of weights on vibration amplitudes

Matrix of weights on the rate of change of control amplitudes from one control iteration to the next

Location along blade span about which trailing edge flap is centered

Horizontal offset of fuselage aerodynamic center and fuselage center of gravity from hub

Vector of vibration amplitudes

Vertical offset of fuselage aerodynamic center and fuselage center of gravity from hub

$\beta_{p} \quad$ Blade precone angle

$\gamma \quad$ Lock number

$\delta \quad$ Flap deflection

$\delta_{\text {limit }} \quad$ Flap deflection limiting value

$\delta_{N c}, \delta_{N c} \quad$ Cosine and sine amplitudes of Nth harmonic of flap deflection, respectively 


$\begin{array}{ll}\delta_{o p t} & \text { Optimal flap deflection } \\ \mu & \text { Advance ratio } \\ \sigma & \text { Rotor solidity ratio } \\ \psi & \text { Blade azimuth angle } \\ \Omega & \text { Rotor angular velocity }\end{array}$

\section{Introduction}

In recent years, researchers have investigated actively controlled trailing edge flaps as a means for vibration control in helicopter rotors. ${ }^{1 * 3}$ In this approach, appropriate control inputs to the flap modify the aerodynamic loads on the blade to reduce the rotor vibratory hub loads. Earlier research has shown that the partial span, trailing edge flap, shown in Fig. 1, produces the same amount of vibration reduction as individual blade control (IBC) that is implemented by moving the entire blade by pitch inputs provided at its root in the rotating system. ${ }^{4}$ However, the actively controlled flap requires almost an order of magnitude less power for its operation. Furthermore, the practical implementation of the actively controlled flap does not require the extensive modifications to the swashplate that are described in Ref. 5.

For practical implementation, the trend has been to use adaptive materials such as piezoelectric or magnetostrictive actuator devices to actively control the flap. This type of actuation has been considered by several researchers including Spangler and Hall, ${ }^{6}$ Bernhard and Chopra, ${ }^{7}$ Fulton and Ormiston, ${ }^{8}$ and Prechtl and Hall. ${ }^{9}$ The force and stroke producing capability of adaptive materials based actuation is limited. Therefore, the actual flap deflections that are achievable with this type of actuation are expected to fall short of the angles required for maximum vibration reduction. Thus, these actuators will be unable to produce the control authority required for optimal vibration reduction, and the actuator is likely to encounter saturation.

In this study, the consequences of imposing limits on the flap deflection produced by the actuator are examined. The influence of such limits, typically denoted as saturation in the control terminology, on vibration reduction capability is assessed. Three methods of constraining flap deflections to limiting values are studied. Two methods for limiting flap deflection amplitudes given an optimal flap deflection history for vibration reduction are: (1) clipping of the optimal flap deflection such that deflections greater than a prescribed value are simply set to the prescribed maximum value, and (2) uniformly scaling down the amplitudes of the flap input harmonics so that the flap amplitude never exceeds the limiting value. A third flap deflection limiting methodology is developed and studied. In this method, the control procedure is modified to allow the controller to automatically adjust the control weighting matrix. The weighting matrix is adjusted iteratively until the flap deflection is properly constrained.

The issue of flap saturation has not been studied in the literature before, yet it plays a very important role in the practical implementation of vibration reduction using the actively controlled flap (ACF).

\section{Mathematical Model and Method of Solution}

The mathematical model employed in this study represents a rotor with a number of flexible, hingeless blades each of which contains a partial span trailing edge flap as shown in Fig. 1. The model was developed in an earlier study by de Terlizzi and Friedmann. ${ }^{10}$

\section{Structural Dynamic Model}

Each rotor blade is modeled by beam-type finite elements capable of representing a composite rotor blade with a swept tip. The blade structural dynamic model was developed by Yuan and Friedmann. ${ }^{11}$ The model has provisions for an arbitrary cross-sectional shape which is allowed to vary along the span. The model accounts for transverse shear and out of plane warping and can model anisotropic material behavior and composite coupling effects.

\section{Aerodynamic Model}

The aerodynamic model has two main components, calculation of the spanwise aerodynamic loads acting on the blade and the calculation of the nonuniform inflow distribution over the rotor.

The blade section aerodynamic loads are determined using two different aerodynamic models. For the quasi-steady loads acting on the blade/flap combination, a modification of Theodorsen's quasisteady aerodynamic theory which includes the influence of the trailing edge flap as developed by Millot and Friedmann ${ }^{1}$ is used. To model the unsteady compressible airloads acting on the blade/flap combination, the aerodynamic theory developed by Myrtle and Friedmann ${ }^{3}$ is employed.

The nonuniform inflow distribution is calculated from a free wake model that has been extracted from the comprehensive rotorcraft analysis tool, CAMRAD/JA, ${ }^{12}$ and modified to be compatible 
with the aeroelastic response analysis employed in this study. It consists of a wake geometry model and a wake computation model that, given the wake geometry, calculates the induced velocity distribution. The free wake geometry routine was initially developed by Scully ${ }^{13}$ and the wake calculation model was developed by Johnson. ${ }^{14}$ The model is based on a vortex lattice approximation of the wake.

\section{Trailing Edge Flap}

Actively controlled flaps have been incorporated into the model in a manner described in Ref. 10. Control inputs provided to the flap consist of a combination of $2 / \mathrm{rev}, 3 / \mathrm{rev}, 4 / \mathrm{rev}$ and $5 / \mathrm{rev}$ flap deflections. These inputs are typically obtained from a control law ${ }^{15}$ based on the minimization of a quadratic performance index composed of vibration and control amplitudes.

\section{Method of Solution}

A modal analysis is implemented using eight free vibration modes of a rotating beam, 3 flap, 2 leadlag, 2 torsional and 1 axial mode. Either a harmonic balance technique or a time domain solution is used to solve the blade response equations depending on whether or not unsteady aerodynamics are employed. In the harmonic balance technique, the blade motions and trim equations are converted into a system of nonlinear algebraic equations and are then solved simultaneously by the IMSL nonlinear algebraic solver DNEQNF. ${ }^{16}$ In the time domain aeroelastic response solution, the equations of motion are numerically integrated using the general purpose Adams-Bashfort ordinary differential equation solver DE/STEP.

\section{Control}

\section{Control Algorithm}

The control algorithm used in this study is one that is typically used in HHC and IBC studies and is described in detail in Ref. 15. It is based on the minimization of a performance index that is a quadratic function of vibrations $\vec{z}_{i}$ and control inputs $\vec{u}_{i}$. The quadratic function is given by:

$$
J=\vec{z}_{i}^{T} \mathbf{W}_{\mathbf{z}} \vec{z}_{i}+\vec{u}_{i}^{T} \mathbf{W}_{\mathbf{u}} \vec{u}_{i}+\Delta \vec{u}_{i}^{T} \mathbf{W}_{\Delta \mathbf{u}} \Delta \vec{u}_{i}
$$

where $\Delta \vec{u}_{i}=\vec{u}_{i}-\vec{u}_{i-1}$. The weighting matrices, $\mathbf{W}_{\mathbf{z}}, \mathbf{W}_{\mathbf{u}}$ and $\mathbf{W}_{\Delta \mathbf{u}}$, used in this study are diagonal and assign the relative importance of the various vibration components and control inputs. $\mathbf{W}_{\boldsymbol{\Delta} \mathbf{u}}$ constrains the rate of change of the control from one control iteration to the next.

The optimal control is found by setting the gradient of the performance index $J$ with respect to the control $\vec{u}_{i}$ to zero:

$$
\frac{\partial J}{\partial \vec{u}_{i}}=0
$$

The solution of this equation results in the optimal control $\vec{u}_{i}^{*}$ that minimizes $J$. It is assumed in this study that the control inputs and vibration levels are known.

To determine the gradient of the performance index with respect to the control, it is necessary to know the gradient of the vibrations with respect to the control. To this end, the vibrations are linearized about the current control input $\vec{u}_{i}$

$$
\vec{z}(\vec{u})=\vec{z}\left(\vec{u}_{i}\right)+\mathbf{T}_{i}\left(\vec{u}-\vec{u}_{i}\right)
$$

where

$$
\mathbf{T}=\frac{\partial \vec{z}}{\partial \vec{u}}
$$

The transfer matrix $\mathbf{T}$ is the Jacobian of the vibration response with respect to the current control input. This Jacobian is calculated numerically using the finite difference method.

Substituting this model of the vibration response into the performance index and minimizing with respect to the control produces the optimal control for the given control step:

$$
\vec{u}_{i+1}^{*}=-\mathbf{D}_{i}^{-1}\left\{\mathbf{T}_{i}^{T} \mathbf{W}_{\mathbf{z}}\left[\vec{z}_{i}-\mathbf{T}_{i} \vec{u}_{i}^{*}\right]-\mathbf{W}_{\Delta \mathbf{u}} \vec{u}_{i}^{*}\right\}
$$

where

$$
\mathbf{D}_{i}=\mathbf{T}_{i}^{T} \mathbf{W}_{\mathbf{z}} \mathbf{T}_{i}+\mathbf{W}_{\mathbf{u}}+\mathbf{W}_{\Delta \mathbf{u}}
$$

This procedure is started by setting the initial optimal control input to zero and repetitively applying Eq. 5 until the optimal control input converges. The resulting control vector is the optimal control vector for the given weighting matrices.

\section{Vibration Measure and Control Input}

In this study, the control law is used to simultaneously reduce the $4 / \mathrm{rev}$ components of the hub loads. Therefore, the vibration vector $\vec{z}$ contains the sine and cosine components of the three $4 / \mathrm{rev}$ hub shears and the three $4 / \mathrm{rev}$ hub moments.

The vibration control is implemented through an actively controlled trailing edge flap on the blade. The flap deflection is composed of $2,3,4$ and $5 / \mathrm{rev}$ harmonic components and can be expressed as:

$$
\delta(\psi)=\sum_{N=2}^{5}\left[\delta_{N c} \cos (N \psi)+\delta_{N s} \sin (N \psi)\right]
$$


It is assumed that all four rotor blades are identical and that the actively controlled flap on each blade executes the same motion for a given blade azimuth angle.

The control input $\vec{u}$ used for vibration reduction in the control algorithm is the vector containing the cosine and sine amplitudes of the $\mathrm{N} / \mathrm{rev}$ flap deflection harmonics. This vector is given by:

$$
\vec{u}=\left\{\delta_{2 c}, \delta_{2 s}, \delta_{3 c}, \delta_{3 s}, \delta_{4 c}, \delta_{4 s}, \delta_{5 c}, \delta_{5 s}\right\}^{T}
$$

\section{Constraining Flap Deflection}

Three different methods for limiting flap deflection to account for actuator saturation are studied. Two of these methods take the computed unconstrained optimal control and obtain the limited flap deflection history in one step through either truncation or amplitude scaling. The first method simply clips the flap deflection at the limiting amplitude for any optimal control command that exceeds this maximum value. The flap deflection is thus described by:

$\delta(\psi)= \begin{cases}\delta_{o p t}(\psi), & \left|\delta_{o p t}(\psi)\right|<\delta_{\text {limit }} \\ \operatorname{sgn}\left(\delta_{\text {opt }}(\psi)\right) * \delta_{\text {limit }}, & \left|\delta_{\text {opt }}(\psi)\right| \geq \delta_{\text {limit }}\end{cases}$

or if the limit of minimum deflection differs from the limit of maximum deflection,

$$
\delta(\psi)= \begin{cases}\delta_{\min }, & \delta_{o p t}(\psi) \leq \delta_{\min } \\ \delta_{o p t}(\psi), & \delta_{\min }<\delta_{o p t}(\psi)<\delta_{\max } \\ \delta_{\max }, & \delta_{o p t}(\psi) \geq \delta_{\max }\end{cases}
$$

The second method for limiting flap deflection uniformly scales down the optimal control flap deflection. Each harmonic component of the optimal flap deflection is scaled by a common factor to limit the maximum flap deflection to the desired amplitude. For this case, the flap deflection is described by:

$$
\delta(\psi)=\frac{\delta_{\text {limit }}}{\max \left(\left|\delta_{\text {opt }}\right|\right)} * \delta_{\text {opt }}(\psi)
$$

where $\max \left(\left|\delta_{\text {opt }}\right|\right)$ is the maximum amplitude of the optimal flap deflection over the entire range of blade azimuth values.

In the first two limiting methods, no constraints are imposed on the flap deflection through the use of the weighting matrix, $\mathbf{W}_{\mathbf{u}}$, in the optimal control calculation. Though the sole purpose of the weighting matrix, $\mathbf{W}_{\mathbf{u}}$, is to constrain flap deflections, it is not possible to know a priori the proper weighting matrix that constrains the flap deflection amplitude to be within prescribed limits. A third flap amplitude limiting method was developed where a new control procedure automatically adjusts the weighting to properly constrain the flap deflection amplitude. The structure of the new procedure is compared to the two previous limiting methods in Figure 2.

In the new control procedure, the optimal control $u^{*}$ is calculated for a given set of parameters in the same way as in the old method. However, after the optimal control is obtained, the maximum and minimum flap deflections for the given control are calculated. The maximum and minimum flap deflections are compared to the prescribed limiting values and a test is performed to determine whether the flap deflections are properly constrained. This test consists of ensuring that the maximum flap deflection is less than the limiting maximum value and the minimum flap deflection is greater than the limiting minimum value. An additional test is performed such that the difference between one of the flap deflection extremes, minimum or maximum, and its corresponding limiting value must be within a user defined $\epsilon$ degrees. This additional criterion ensures that the flap is not over constrained and allows the full allotted control authority for vibration reduction. If the flap deflection is overconstrained or underconstrained, the weighting matrix is appropriately modified to relax or tighten the flap deflection constraint. The new weighting matrix is input into the optimal control calculation routine and the procedure repeats until the flap is properly constrained.

For this new control procedure, a simple form of the weighting matrix is used. The weighting matrix is assumed to be a scalar times the identity matrix. The weighting matrix is therefore described by:

$$
\mathbf{W}_{\mathbf{u}}=c_{w u} \mathbf{I}
$$

All harmonic components of the flap deflection are equally weighted. The controller manipulates the scalar multiplier to provide the proper flap constraints. If the flap deflection is overconstrained, the controller reduces the value of $c_{w u}$ and a new optimal control is calculated. If the flap deflection is underconstrained, the controller increases the value of $c_{w u}$ and a new optimal control is calculated. The iterative procedure reduces or increases $c_{w u}$ until the optimal control converges to the desired deflection limits within a prescribed tolerance.

\section{Results}

Simulations were performed for both a low speed condition, $\mu=0.15$, and a higher cruise speed condition, $\mu=0.30$, using quasi-steady aerodynamics. 
The results are obtained for a four bladed rotor consisting of straight, hingeless blades having the properties given in Table 1. Each actively controlled trailing edge flap has a chord length one quarter that of the blade chord and a span of $12 \%$ of the blade span, centered about the $3 / 4$ blade span location.

\section{Low Speed Results}

For the $\mu=0.15$ flight condition, vibratory hub loads for a number of test cases are shown in Figures 3 and 4 . Two values of maximum flap deflection are investigated for their influence on vibration reduction capabilities of the actively controlled flap. Results with a maximum flap deflection of 2 degrees are shown in Figure 3 while Figure 4 provides results with a maximum flap deflection of 4 degrees. The uncontrolled, or baseline, $4 / \mathrm{rev}$ vibratory hub shears and moments are presented in the figures along with the results from four actively controlled flap simulations. The unweighted control results are obtained by setting the control weighting matrices $\mathbf{W}_{\mathbf{u}}$ and $\mathbf{W}_{\Delta \mathrm{u}}$ identically to zero matrices. This produces a best case scenario for vibration reduction with no limitation on either control amplitude or the rate of change of control amplitude from one control iteration to the next.

The flap deflection history as a function of azimuth for the unweighted optimal control is shown in Fig. 5. The flap deflection is shown for the range of azimuth values from 0 to 360 degrees. Flap deflection is periodic in this study so the flap deflection is identical for each successive rotor revolution. As seen in Fig. 3, the unweighted control flap deflection significantly reduces vibratory hub loads from the baseline values. Hub loads are reduced by a minimum of $24 \%$ for the yawing moment to a maximum of $98 \%$ for the vertical shear. Overall hub vibration is reduced to $8 \%$ of the uncontrolled level. However the flap deflection history indicates that flap deflection amplitudes of up to 19.5 degrees are required. This is much greater than what is currently achievable by adaptive materials based actuation of the flap.

The effects on vibration levels of limiting the flap deflection to a maximum of 2 degrees through either the clipping, scaling or automatic weighting methods, as described previously, are shown in Fig. 3. With the clipping method, or 'truncated control', vibratory hub loads are reduced by a maximum of $49 \%$ in yawing moment to an increase in vertical shear of $12 \%$. The overall hub vibration level is reduced by only $15 \%$. The flap deflection history for this control is shown in Figure 6. The flap deflection history for the uniform scaling of the unweighted flap deflection amplitude to a maximum of 2 degrees is shown in Fig. 7. This control input reduces vibration levels from as little as $0 \%$ in the yawing moment to as much as $15 \%$ in the lateral and vertical shears. Overall hub vibration is reduced to $87 \%$ of the uncontrolled value. Clearly neither of these flap deflection limitation methods do a good job in reducing hub vibrations. The overall vibrations are from 10.7 to 11.0 times greater than the unweighted control. The flap deflection history for the automatic weighting method is shown in Fig. 8 . With the automatic adjustment of the control weighting matrix, vibrations are reduced by a minimum of $8 \%$ in yawing moment to a maximum of $91 \%$ in longitudinal shear. Overall hub vibration is reduced to $36 \%$ of the uncontrolled level. Vibrations with the automatic weighting method are less than half of those obtained with either of the other two deflection limiting methods.

The effects on vibration levels of limiting the flap deflection to a maximum of 4 degrees through the three limiting methods are shown in Figure 4. With the unweighted flap deflection truncated at $4 \mathrm{dc}-$ grees, shown in Fig. 9, vibratory hub loads are reduced by a minimum of $8 \%$ in vertical shear to a maximum of $90 \%$ in lateral shear. Overall hub vibration is reduced to $54 \%$ of the uncontrolled value. The flap deflection history for the uniform scaling of the unweighted flap deflection amplitude to a maximum of 4 degrees is shown in Fig. 10. With this control, vibratory hub loads are reduced by a minimum of $8 \%$ in pitching moment to a maximum of $30 \%$ in lateral shear. Overall hub vibration is reduced to $76 \%$ of the uncontrolled level. With the automatic adjustment of the weighting matrix to constrain maximum flap deflection to 4 degrees, vibratory hub loads are reduced by a minimum of $2 \%$ in yawing moment to a maximum of $97 \%$ in vertical shear. Overall hub vibration is reduced to $18 \%$ of the uncontrolled value. The flap deflection history for this control is shown in Fig. 11.

With a 4 degree deflection limitation, the clipping and scaling control methods reduce vibrations below the levels obtained with a 2 degree flap limitation. However, neither method reduces vibrations to even half of the uncontrolled levels. The control with automatic adjustment of the weighting matrix produces overall vibration levels that are one third of the clipping method vibrations and one fourth of the scaling method vibrations with the same maximum flap amplitude of 4 degrees. 


\section{High Speed Results}

For the $\mu=0.30$ flight condition, vibratory hub loads are shown in Figures 12 and 13. As in the low speed case, two values of maximum flap deflection are investigated for their influence on vibration reduction capabilities of the actively controlled flap. Results with a maximum flap deflection of 2 degrees are shown in Figure 12 while Figure 13 shows results with a maximum flap deflection of 4 degrees. The uncontrolled 4/rev vibratory hub shears and moments are plotted in the figures along with the results from four actively controlled flap simulations as studied in the low speed case. The flap deflection history for the unweighted optimal control is shown in Fig. 14. The flap deflection history indicates that flap deflection amplitudes of up to 9.2 degrees are required for vibration reduction. Hub loads are reduced by a minimum of $84 \%$ for the pitching moment to a maximum of $97 \%$ for the vertical shear. Overall hub vibration is reduced to $9 \%$ of the uncontrolled level.

The effects on vibration levels of limiting the flap deflection to 2 degrees are shown in Fig. 12. The flap deflection history for the unweighted optimal control truncated at two degrees is shown in Fig. 15. With the truncated control, vibratory vertical shear is reduced by $34 \%$ while all other components are greater than the uncontrolled values. The overall hub vibration level is actually increased by $5 \%$. The flap deflection history for the unweighted control uniformly scaled to a maximum of 2 degrees is shown in Fig. 16. This control input reduces vibration levels from as little as $21 \%$ in lateral shear and yawing moment to as much as $27 \%$ in longitudinal shear. Overall hub vibration is reduced to $76 \%$ of the uncontrolled value. As with the low speed case, neither of these flap deflection limitation methods do a good job in reducing hub vibrations.

The flap deflection history for the automatically adjusted weighting matrix method is shown in Fig. 17. With this control, vibration levels are reduced by a minimum of $64 \%$ in pitching moment to a maximum of $91 \%$ in longitudinal shear. Overall hub vibration is reduced to $15 \%$ of the uncontrolled level. This vibration reduction is significantly better than either of the other two deflection limiting methods. The overall vibration is less than a fifth the level of the other two methods.

The effects on vibration levels of limiting the flap deflection to a maximum of 4 degrees through the three limiting methods are shown in Figure 13. With the unweighted flap deflection truncated at 4 degrees, shown in Fig. 18, vibratory hub loads are re- duced by a minimum of $12 \%$ in lateral shear to a maximum of $85 \%$ in vertical shear. Overall hub vibration is reduced to $59 \%$ of the uncontrolled value. The flap deflection history for the uniform scaling of the unweighted flap deflection amplitude to a maximum of 4 degrees is shown in Fig. 19. With this control, vibratory hub loads are reduced by a minimum of $38 \%$ in rolling moment to a maximum of $49 \%$ in longitudinal shear. Overall hub vibration is reduced to $59 \%$ of the uncontrolled level. The flap deflection history for the control with the automatic adjustment of the weighting matrix to constrain maximum flap deflection to 4 degrees is shown in Fig. 20. With this control, vibratory hub loads are reduced by a minimum of $79 \%$ in pitching moment to a maximum of $97 \%$ in vertical shear. Overall hub vibration is reduced to $10 \%$ of the uncontrolled value. This reduction in overall hub vibration is nearly the same as that of the unweighted optimal control but requires a maximum flap deflection that is less than half that of the unweighted optimal control. This overall vibration level is one sixth that of the vibrations from either of the other two limited flap amplitude control methods with the same maximum flap deflection of 4 degrees.

It is evident that neither of the two simple flap deflection limiting methods, clipping or amplitude scaling, provides the optimal control flap deflection for a given maximum amplitude of deflection. The automatic adjustment of the control weighting matrix performs much better in vibration reduction than the two other methods of deflection limiting.

\section{Concluding Remarks}

Simulations on a rotor with actively controlled trailing edge flaps were conducted to investigate the influence on vibration reduction of actuators with limited ability to produce flap deflection. The study considered a four bladed rotor with hingeless, isotropic blades incorporating fully coupled flap-lagtorsional dynamics. Simultaneous reduction of the vibratory hub moments was achieved through the minimization of a quadratic performance index consisting of weighted squares of vibration magnitudes and control amplitudes. Three means of limiting the maximum flap deflection were investigated. The most important conclusions obtained in this study are summarized below:

1. The actively controlled, partial span, trailing edge flap with no constraints on control effort provides significant reduction of the $4 / \mathrm{rev}$ vibratory hub loads. For both low and high speed

6

American Institute of Aeronautics and Astronautics 
cases, overall vibrations were reduced to less than $10 \%$ of the uncontrolled levels. This unweighted control required flap deflections that are unachievable with the current state of the art in adaptive materials based actuation. At an advance ratio of $\mu=0.15$, flap deflections of up to 20 degrees were required. These deflections are much greater than the expected maximum deflections with current adaptive materials of less than 5 degrees.

2. Two simple methods for limiting the amplitude of flap deflection were investigated, clipping and amplitude scaling. Neither method proved acceptable for vibration reduction. Scaling the optimal unweighted control down to a limiting maximum deflection reduced all six components of the vibratory hub loads for both speed conditions considered in this study but the vibration reduction was only marginal. The clipping method of limiting flap amplitude actually caused increased vibration levels in many hub load components. Even with a maximum flap deflection of 4 degrees, neither method could reduce vibrations to one half of the uncontrolled value.

3. A new control procedure for vibration reduction with limited flap deflection authority was developed. In this procedure, the control weighting matrix is adjusted automatically by the controller until the resulting flap deflection is within prescribed limits. With this method, vibrations are significantly reduced at both forward flight speeds considered in the study. Overall hub vibration was reduced to $10 \%$ of the uncontrolled level at $\mu=0.30$ with a maximum flap deflection of $\mathbf{4}$ degrees. This reduction in vibrations is nearly the same as that achieved by the unweighted optimal control that required flap deflections of 9.2 degrees.

\section{References}

[1] Millott, T. A. and Friedmann, P. P. , "Vibration Reduction in Helicopter Rotors Using an Actively Controlled Partial Span Trailing Edge Flap Located on the Blade," NASA CR-4611, 1994.

[2] Milgram, J. and Chopra, I. , "Helicopter Vibration Reduction with Trailing Edge Flaps," Proceedings of the 35th AIAA/ASME/ASCE/AHS/ASC Structures,
Structural Dynamics and Materials Conference, New Orleans, LA, April 1995.

[3] Myrtle, T. and Friedmann, P. P. , "Unsteady Compressible Aerodynamics of a Flapped Airfoil with Application to Helicopter $\mathrm{Vi}$ bration Reduction," Proceedings of the 38th AIAA/ASME/ASCE/AHS/ASC Structures, Structural Dynamics and Materials Conference, Kissimmee, FL, April 1997, pp. 224-240.

[4] Friedmann, P. P. and Millott, T. A. , "Vibration Reduction in Rotorcraft Using Active Control: A Comparison of Various Approaches," Journal of Guidance, Control, and Dynamics, Vol. 18, No. 4, 1995, pp. 664 673.

[5] Splettstoesser, W. R. , Schultz, K. J. , van der Wall, B. Buchholz, H. , Gembler, W. , and Niesl, G. , "The Effect of Individual Blade Pitch Control on BVI Noise - Comparison of Flight Test and Simulation Results," Proceedings of the 24th European Rotorcraft Forum, Marseilles, France, September 1998, pp. AC.07 1-AC.07-15.

[6] Spangler, R. L. and Hall, S. R. , "Piezoelectric Actuators for Helicopter Rotor Control," Proceedings of the 31st AIAA Structures, Structural Dynamics and Materials Conference, Long Beach, CA, April 1990, pp. 1589-1599.

[7] Bernhard, A. and Chopra, I. , "Trailing Edge Flap Activated by a Piezo-Induced BendingTorsion Coupled Beam," Journal of the American Helicopter Society, Vol. 44, No. 1, January 1999, pp. 3-15.

[8] Fulton, M. V. and Ormiston, R., "Small-Scale Rotor Experiments with On-Blade Elevons to Reduce Blade Vibratory Loads in Forward Flight," Proceedings of the 54th Annual Forum of the American Helicopter Society, Washington, DC, May 1998, pp. $433-451$

[9] Prechtl, E. F. and Hall, S. R. , "Design of a High Efficiency Discrete Servo-Flap Actuator for Helicopter Rotor Control," Proceedings of the 1998 SPIE Conference on Smart Structures and Integrated Systems, San Diego, CA, March 1997.

[10] de Terlizzi, M. and Friedmann, P. P. , "Aeroelastic Response of Swept Tip Rotors Including the Effects of BVI," Proceedings of the 54th Annual Forum of the American Helicopter Society, Washington, DC, May 1998, pp. 644-663. 
[11] Yuan, K. A. and Friedmann, P. P. , "Aeroelasticity and Structural Optimization of Composite Helicopter Rotor Blades with Swept Tips," NASA CR-4665, 1995.

[12] Johnson, W. , A Comprehensive Analytical Model of Rotorcraft Aerodynamics and Dynamics, Vol. I: Theory Manual. Johnson Aeronautics, Palo Alto, CA, 1988.

[13] Scully, M. P. , "Computation of Helicopter Rotor Wake Geometry and its Influence on Rotor Harmonic Airloads," Ph.D. Dissertation, Aeroelastic Research Laboratory, Massachusetts Institute of Technology, 1975.

[14] Johnson, W. , "Wake Model for Helicopter Rotors in High Speed Flight," NASA CR-177507, 1988 .

[15] Johnson, W. , "Self-Tuning Regulators for Multicyclic Control of Helicopter Vibrations," NASA TP-1996, 1982.

[16] --, IMSL Library: Reference Manual. IMSL Inc., Houston, TX, 1980.

Table 1: Soft-in-plane Isotropic Rotor Blade Data

\begin{tabular}{ll}
\hline \hline Rotor Data \\
$E I_{y} / m \Omega^{2} R^{4}=0.0106$ & \\
$E I_{z} / m \Omega^{2} R^{4}=0.0301$ & \\
$G J / m \Omega^{2} R^{4}=0.001473$ & \\
$n_{b}=4$ & $a=2 \pi$ \\
$\gamma=5.5$ & $\beta_{p}=0.0$ \\
$\sigma=0.07$ & $c_{b} / R=0.055$ \\
Helicopter Data & \\
\hline$C_{W}=0.00515$ & $C_{d 0}=0.01$ \\
$Z_{F C} / R=0.50$ & $Z_{F A} / R=0.25$ \\
$X_{F C} / R=0.0$ & $X_{F A} / R=0.0$ \\
Flap Data & \\
\hline$L_{c s}=0.12 L_{b}$ & $c_{c s}=c_{b} / 4$ \\
$\mathrm{x}_{c s}=0.75 L_{b}$ & \\
\hline \hline
\end{tabular}

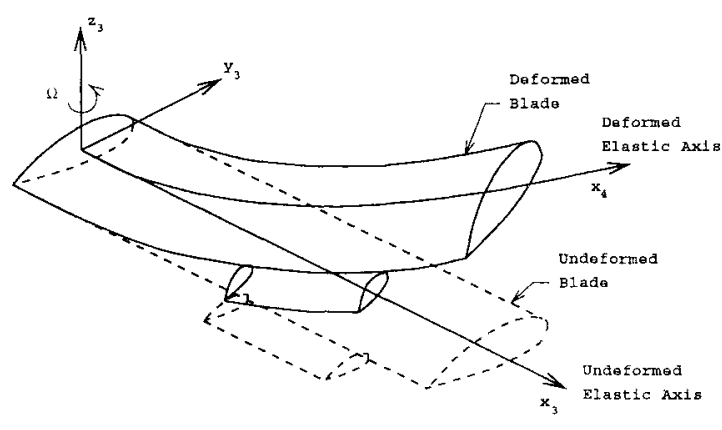

Figure 1: Fully elastic blade model incorporating a partial span trailing edge flap.

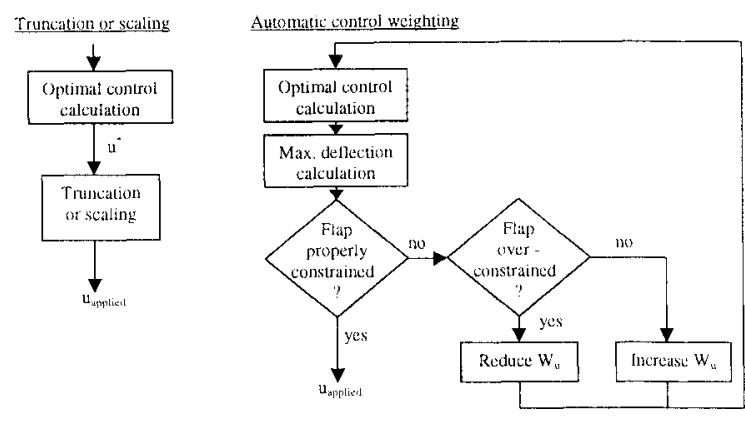

Figure 2: Flap deflection limiting methodologies

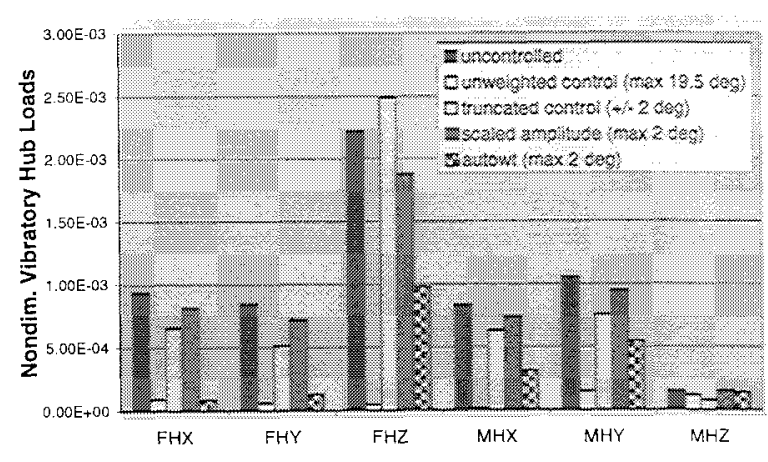

Figure 3: Vibratory hub loads with 2 degree saturation $-\mu=0.15$ 


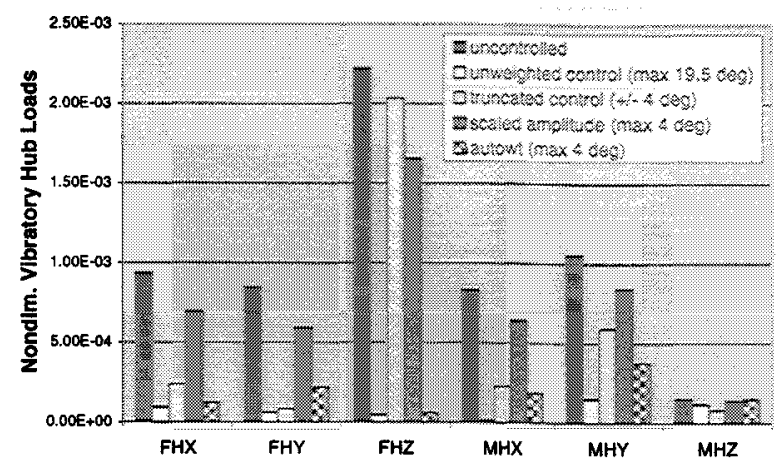

Figure 4: Vibratory hub loads with 4 degree saturation $-\mu=0.15$

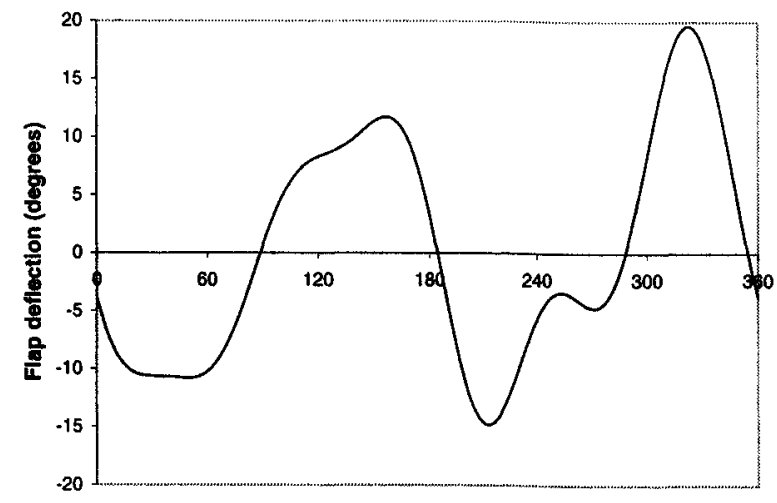

Figure 5: Unweighted flap deflection as a function of azimuth $-\mu=0.15$

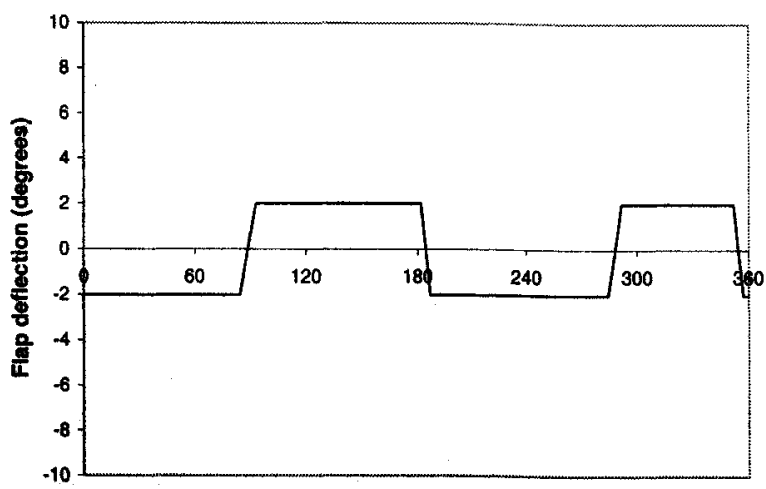

Figure 6: Unweighted flap deflection truncated at 2 degrees $-\mu=0.15$

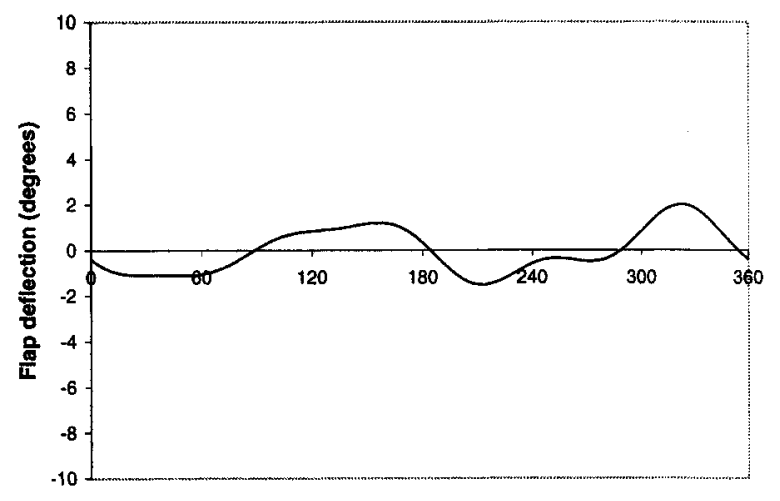

Figure 7: Scaled to 2 degrees flap deflection as a function of azimuth $-\mu=0.15$

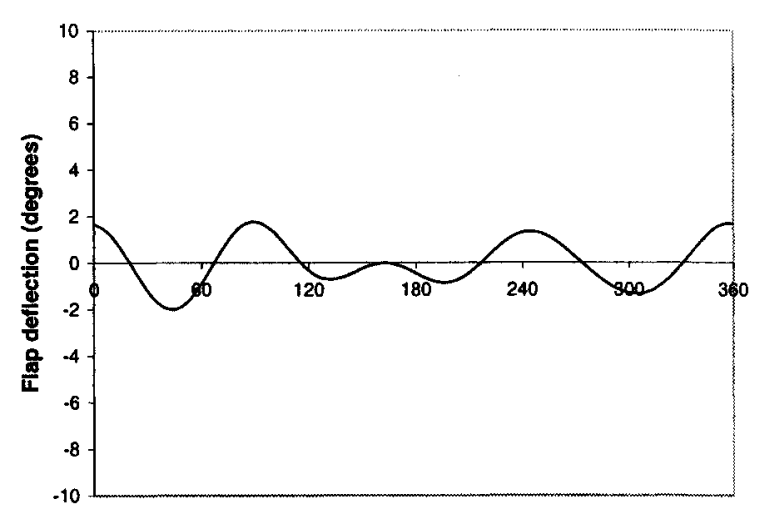

Figure 8: Flap deflection with 2 degree limiting automatic weighting $-\mu=0.15$

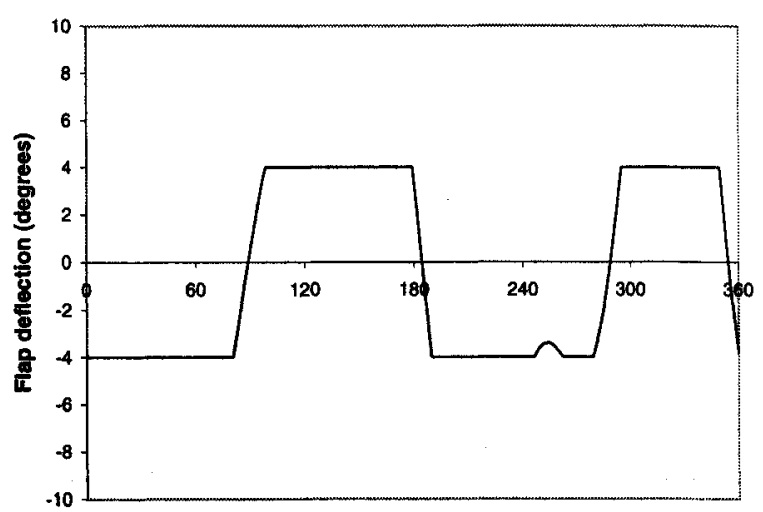

Figure 9: Unweighted flap deflection truncated at 4 degrees $-\mu=0.15$

9

American Institute of Aeronautics and Astronautics 


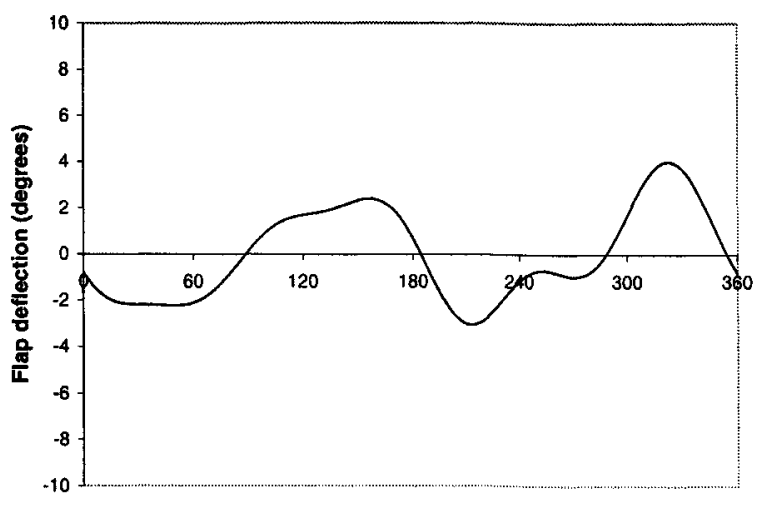

Figure 10: Scaled to 4 degrees flap deflection as a function of azimuth $-\mu=0.15$

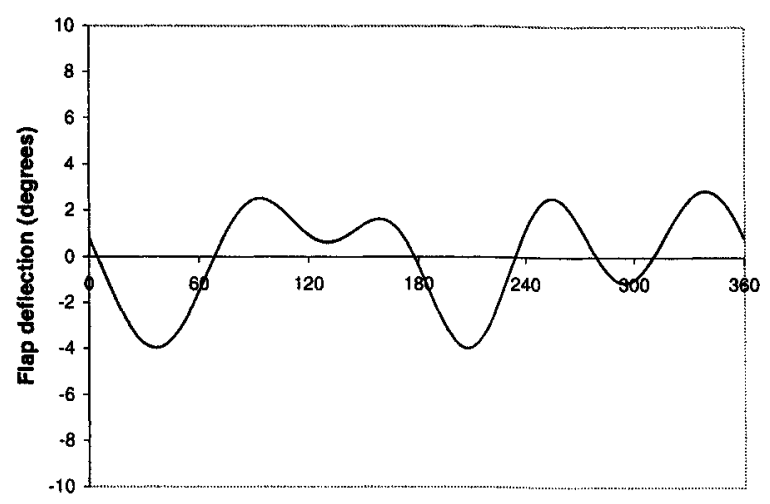

Figure 11: Flap deflection with 4 degree limiting automatic weighting $-\mu=0.15$

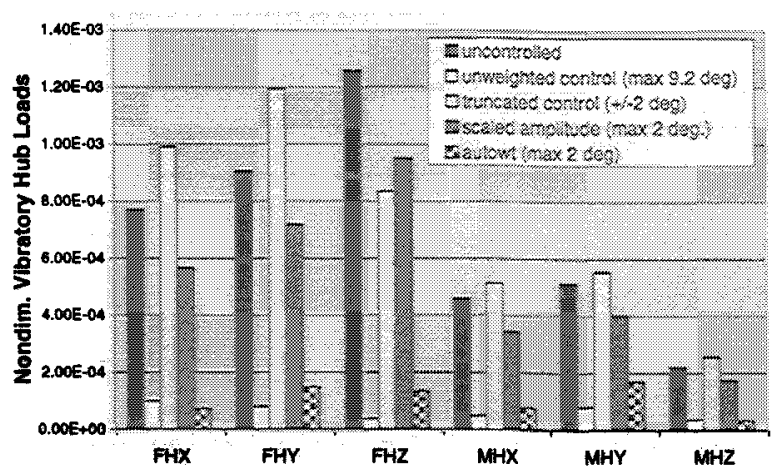

Figure 12: Vibratory hub loads with 2 degree saturation $-\mu=0.30$

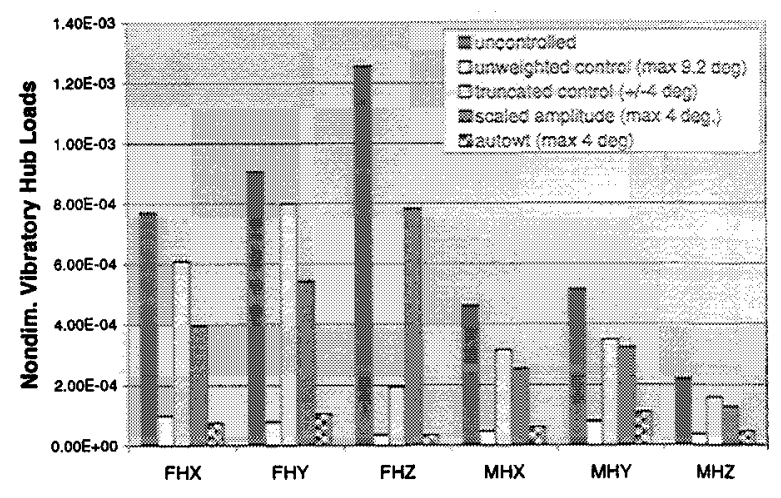

Figure 13: Vibratory hub loads with 4 degree saturation $-\mu=0.30$

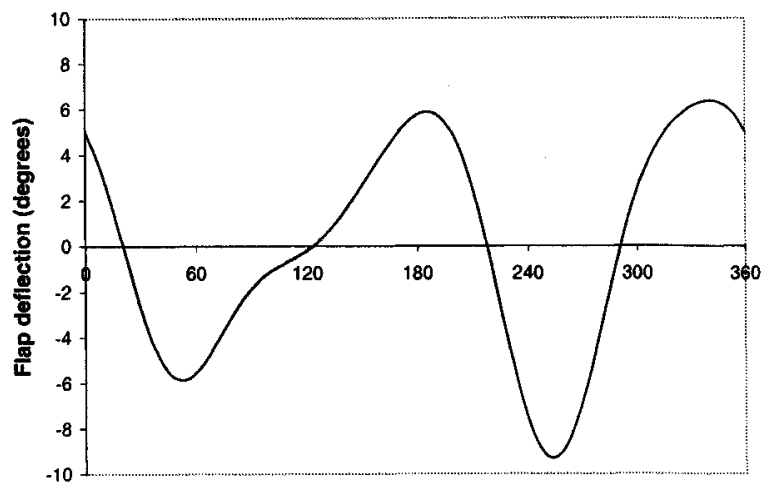

Figure 14: Unweighted flap deflection as a function of azimuth $-\mu=0.30$

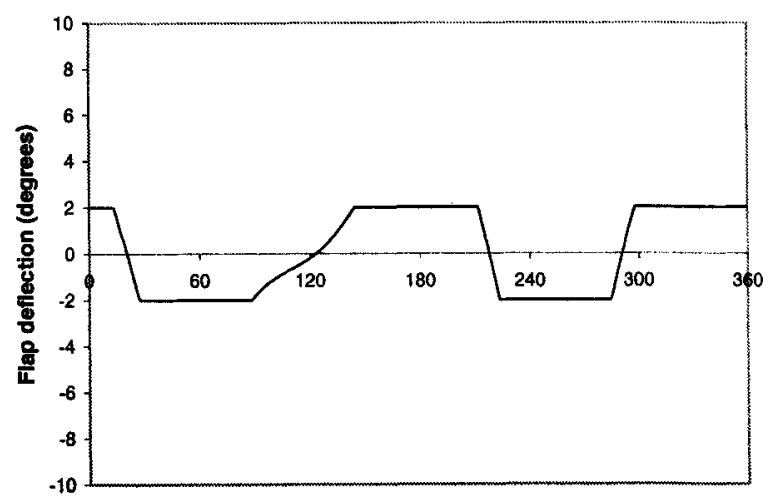

Figure 15: Unweighted flap deflection truncated at 2 degrees $-\mu=0.30$ 


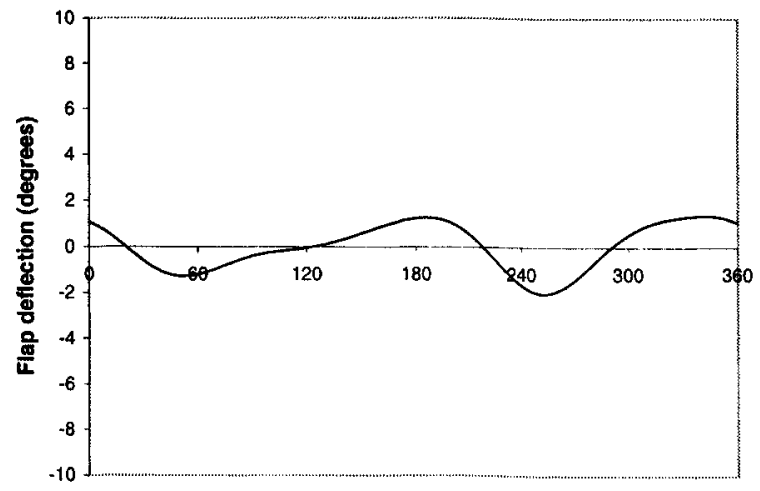

Figure 16: Scaled to 2 degrees flap deflection as a function of azimuth $-\mu=0.30$

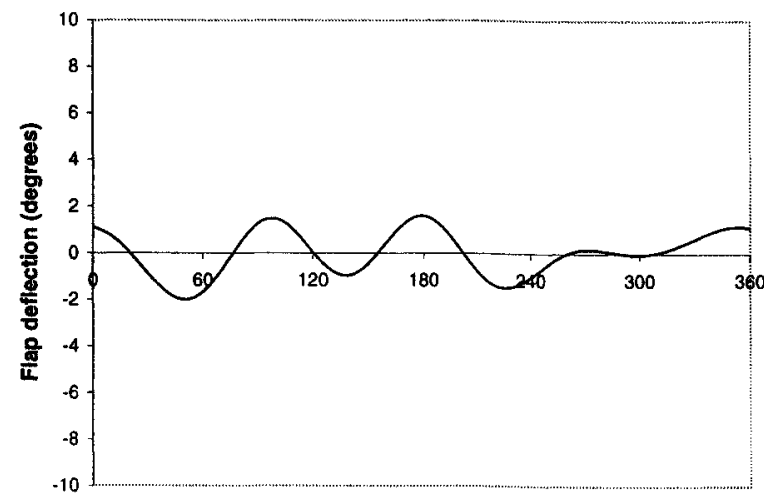

Figure 17: Flap deflection with 2 degree limiting automatic weighting $-\mu=0.30$

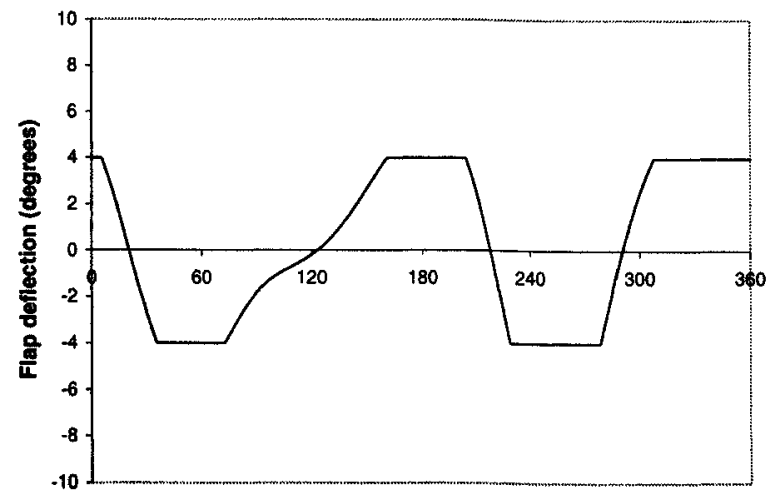

Figure 18: Unweighted flap deflection truncated at 4 degrees $-\mu=0.30$

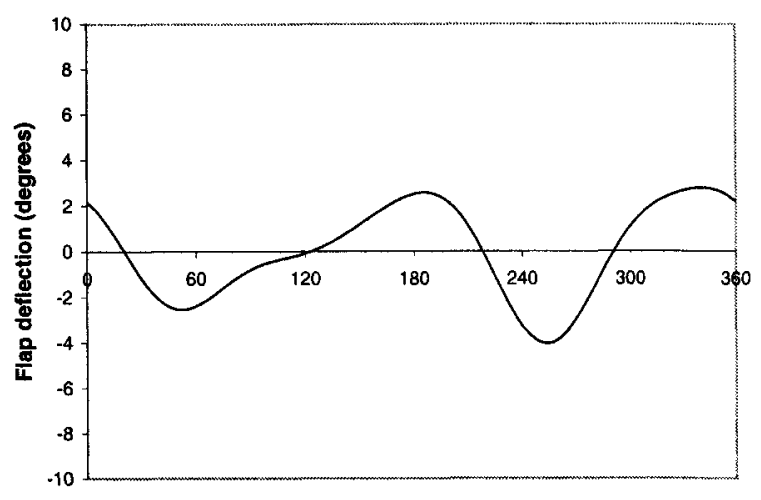

Figure 19: Scaled to 4 degrees flap deflection as a function of azimuth $-\mu=0.30$

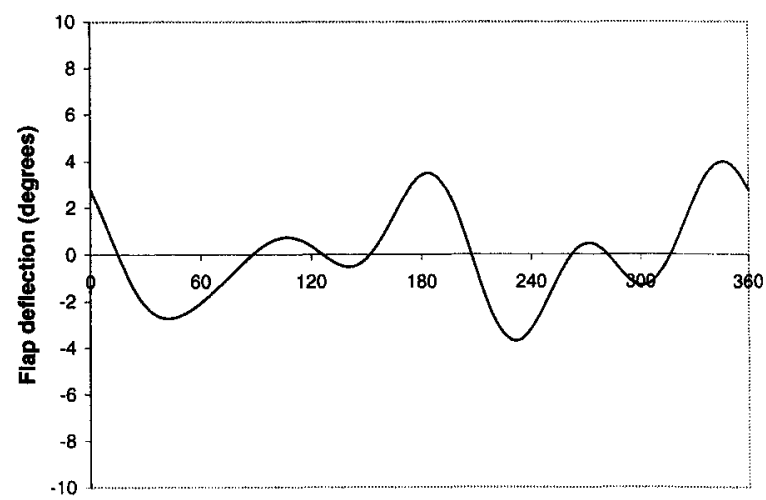

Figure 20: Flap deflection with 4 degree limiting automatic weighting $-\mu=0.30$ 